\title{
Development of Methods for Forecasting Tourist Flows
}

\author{
A.M. Kanina* \\ Novosibirsk State Technical University \\ *Corresponding author. Email: kanina@ corp.nstu.ru

\begin{abstract}
The tourist flow to Russia in 2019 was to grow by $20 \%$, as predicted by the Association of Tour Operators of Russia (ATOR), as a result, 18\% visited Russia. Tourism experts need to develop a methodology for forecasting tourist flows that can calculate potential tourists interested in traveling in Russia, and in the future, forecast demand and make appropriate recommendations for federal and regional authorities and the tourism business. This analysis offers additional indicators characterizing tourist flows, allowing us to predict and evaluate the tourist flow in the territory of individual regions, as well as the concept of a methodology for forecasting tourist flows.
\end{abstract}

Keywords: forecasting tourist flow, inbound tourism, statistical indicators, tourist demand, predictive

methodology

\section{INTRODUCTION}

In January 2020, the new head of government M.V. Mishustin signed a document according to which experts in the tourism sector will have to work out the basic concepts of "tourist flow", "inbound tourist flow" and develop a unified methodology for calculating the tourist flow. The use of this technique should already begin by winter of 2021.[1]

Note that in the draft decree of the Government of the Russian Federation, the federal target program "Development of domestic and inbound tourism in the Russian Federation (2019-2025)", tourist flow is defined as the aggregate number of accommodated citizens of the Russian Federation in collective accommodation facilities and the number of tourist trips for citizens of neighboring countries and beyond.

Currently, at the federal level there is no methodology for forecasting tourist flows, as well as a model for the formation of additional indicators for tracking tourist flow. In the territory of the Russian Federation, there is an official statistical methodology for estimating the number of incoming and outgoing tourist trips adopted by Rosstat in 2014, based on the accounting of Russian and foreign tourists in hotels and other collective accommodation facilities.[2]

One of the main indicators for inbound flows is the number of tourists arriving, namely the total number of tourists arriving in the Russian Federation, and the indicators of expenditures (expenses for hotel accommodation, transportation services, visa support, expenses for sightseeing, shopping) for tourists in destinations are also considered.

However, these are statistical indicators that cannot be easily obtained in practice by a separate tourism company, due to the lack of measures to collect additional information, as well as accounting for tourism costs in the Russian Federation.

Consider other sources of information that are used to analyze the tourist flow, namely, transport statistics, statistics of the General Directorate for Migration of the Ministry of Internal Affairs of the Russian Federation, statistical information of the border service of the Federal Security Service of the Russian Federation, which shows the entry of a foreign citizen into the territory of the Russian Federation.

It is worth noting that the data obtained do not give a clear idea of why and why a tourist comes, in fact, these are secondary data from the point of view of constructing a methodology and assessing potential tourist demand.

Given the current conditions of tourism development, it is necessary to develop indicators for the methodology of forecasting tourist flow, which will contribute to solving a set of theoretical and practical tasks for the development of domestic tourism and increase the turbulence of demand for the Russian product. [3]

In the course of the study, the majority of tourist demand forecasting techniques proposed by foreign and domestic authors are based on the use of econometric approaches (V.A. Minaev and N.A. Platonova on the development of forecasting approaches, econometric approaches De Mello et al (2002), Dritsakis (2003), Huybers (2003), Kulendran и Witt (2001, 2003), Lim and McAleer (2001, 2002), Morley (2000), Papatheodorou (2001), Song и др. (2000, 2003) и Webber (2001)).[4]

\section{QUANTITATIVE INDICATORS OF TOURIST ACTIVITY}

Of all the considered methods, the Zapata G. methodology stands out, which is based on the collection of personalized information about the tourist, to predict 
tourist interest, which helps in making managerial decisions. [5]

From our point of view, it is necessary to develop a methodology that will analyze personal indicators of tourist activity.

A briefly developed methodology can be represented as follows:

1. Identification of incoming information (collection of information from tourism organizations, analysis of search queries on the Internet).

2. Analysis of changes (reports of federal and regional authorities, international trends in the tourism industry).

3. Identification of market opportunities (surveys / monitoring the behavior of tourists);

4. The introduction of new indicators of tourist activity, which are based on digital technology.

5. Development of methods for forecasting tourist flows.

However, to increase the effectiveness of the predictive methodology, it is necessary to work out additional indicators that must be relied upon when drawing up the annual plan for promoting Russian tourism products on international markets.

The modern tourism industry is dynamic in nature, therefore, a predictive methodology for forecasting tourist flows requires indicators that reflect the current state of the market. Next, consider in more detail quantitative indicators.

Quantitative indicators: generally accepted

1. The number of inbound / outbound tourists (traffic of transport organizations)

2. The number of foreign tourists in accommodation facilities (Migration registration of the Ministry of Internal Affairs of the Russian Federation).

3 . The number of tourists arriving at the tourist destination (Statistical information from regional / federal tour operators).

4. The number of tourists in a country / region (Statistics from UNWTO / Rostourism).[6]

Quantitative indicators: recommended

6 . The number of queries with a specific semantic core for each country (Search queries Google trends, Yandex Wordstat);

7. Rating from trendsetters / bloggers in the field of tourism.

8. The number of tourist publications (Thematic and tourist hashtags in social networks Instagram / VK).

9. Rating of frequently mentioned destinations in travel magazines (Analysis of reviews and articles).

10. The number of groups in social networks, as well as the number of subscribers (Analysis of information from social networks)

11. The number of reviews on specialized tourist resources (Analysis of reviews of tourist sites (Tripadviser / Booking)).

We will analyze in more detail each of the proposed indicators. Traffic of transport organizations, in this case, collecting this information is not difficult, since modern airports and Russian Railways keep records of their passengers and regularly provide information to public tourism organizations and not only. The information received will help to form an idea of the entry flow.

The second indicator is the registration of guests from accommodation facilities. According to Russian law, when a foreign tourist settles in, the hotel is obliged to register for migration within 24 hours. Many hotels have already installed additional software, for example, Skala UFMS, Travelline, Bnovo, Hotel.Kontur, etc., which automatically prepare a registration journal and transmit information to the Ministry of Internal Affairs.

The third indicator, namely statistical information from regional and federal tour operators, also depends on the activities of the tour operator. In particular, to forecast tourist demand and formulate a strategic development program, we need data from tour operators who are involved in inbound tourism, i.e. incoming. According to the Federal Tourism Agency at the beginning of 2020 in the Russian Federation, there are about 3191 tour operators companies who are involved in international inbound tourism.[1]

In the course of research and search for new indicators for the tourism market, we examined the indicator of the number of search queries using tools such as Google Trends. Let us analyze this indicator using the example of the tourism potential of the city of Novosibirsk. Novosibirsk is not included in the rating of twenty cities visited by foreign tourists according to Rosstat. According to search queries, the top 15 countries, according to metrics (travel and leisure), include: Armenia, Mongolia, Azerbaijan, Cyprus, Luxembourg, Georgia, Latvia, Slovakia, China, Estonia, Kyrgyzstan, Uruguay, Finland. [7]

The analysis shows that Novosibirsk, as a tourist destination, is of interest to potential foreign tourists, and this demand needs to be highlighted through marketing channels to promote the region. Other indicators, such as a rating from trendsetters, the number of publications with a hashtag of the city, the presence of a group in popular social networks, analysis of reviews, etc., will contribute to the creation of a qualitative model for forecasting the tourist flow. [8]

\section{RESULTS}

The methodology for forecasting the tourist flow is able to calculate potential tourists interested in this area of vacation in Russia, and in the future to forecast demand and make appropriate recommendations for federal and regional authorities and the tourism business. The presented indicators allow us to develop the concept of a forecasting technique, using a marketing-oriented technology that can be represented as a business process with constant verification of information.

This concept is presented below: 

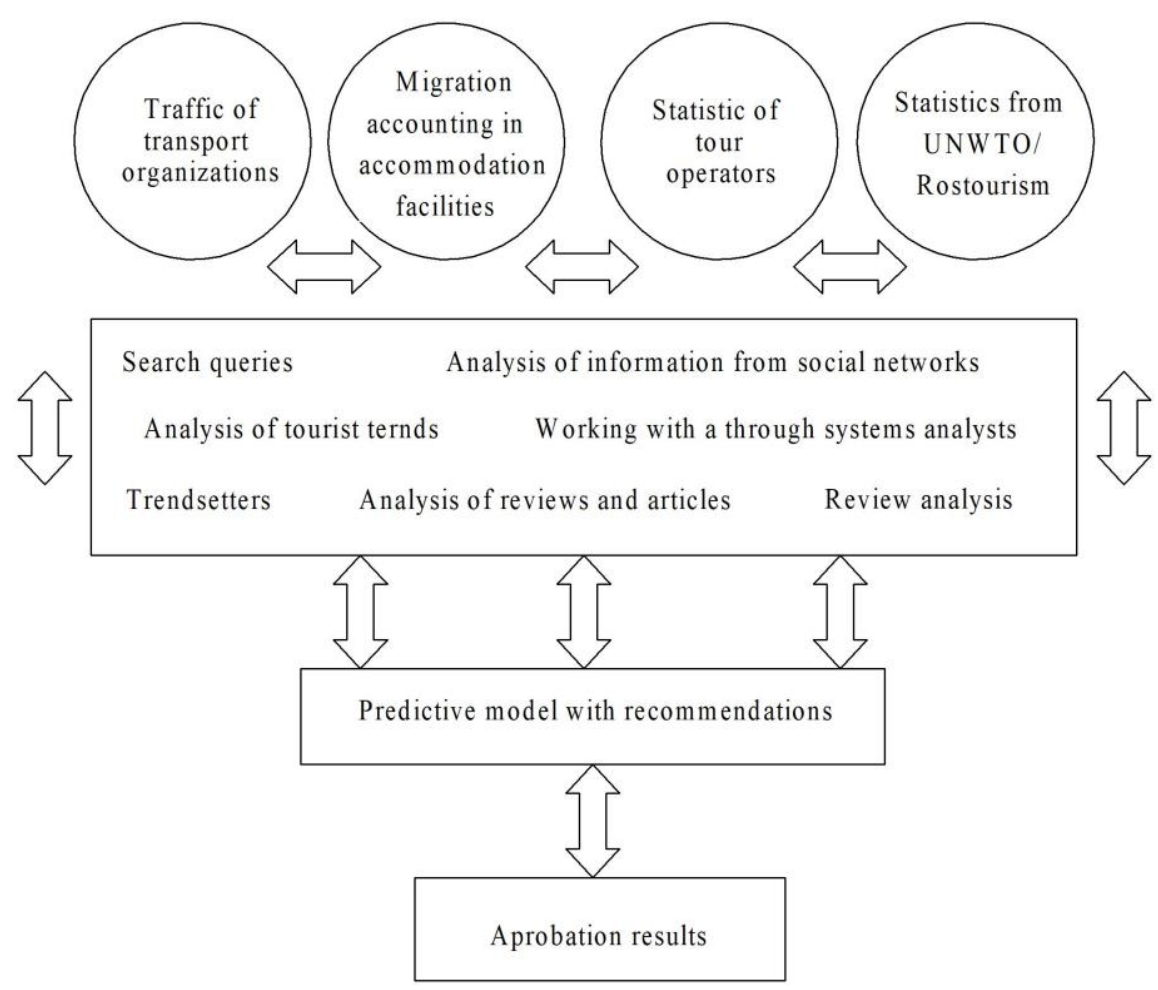

Figure 1 Graphic representation of the methodology for forecasting tourist flows Source: compiled by the author

\section{CONCLUSION}

Application of the proposed concept to forecasting the tourist flow will allow the tourist market not only to maintain the competitive advantages that are already present, but also to ensure its constant competitiveness in a rapidly changing industry.

It is also worth noting that at all stages of this concept, information is verified, which helps to avoid errors in the development of recommendations for the tourism business. Further, from the information received, a forecast model of tourist flows will be formed.

The forecast model will answer a number of questions, such as:

- which tourist flows should be counted on now; - which tourism products need to be developed; - and what tourist flows we need to focus on in the future. The approbation of the results is indicated by a dashed line, since the obtained information can be used to promote the Russian tourism product on the international market with the help of the federal authorities and in this case, the approbation of the received information remains with the authority.

But it, in turn, can also find application in the tourism business, which in the future through iteration will also help to improve the methodology for forecasting tourist flows.

\section{ACKNOWLEDGMENT}

This work was supported by the grant C19-24 from Novosibirsk state technical university.

\section{REFERENCES}

[1] Federal Agency for Tourism [Electronic resource] // Rostourism: [site].URL:https://www.russiatourism.ru/ (accessed: 10/12/2019).

[2] Inbound Tourism Russia 2018 [Electronic resource] // TourStat-studies of the tourism and travel market in Russia and the CIS: [site].

URL:http://turstat.com/inboundtravelrussia6month2018 (accessed: 11/05/2019).

[3] Minaev V.A., Platonova N.A. Regional tourism: forecasting and development planning in modern macroeconomic conditions [Electronic resource] // Cyber-Leninka: [site].

URL:https://cyberleninka.ru/article/n/regionalnyyturizm-prognozirovanie-i-planirovanie-razvitiya-vsovremennyh roekonomicheskih usloviyah (accessed: 10.16.2019). 
[7] Google Trends [Electronic source] // Google Trends: [website].

URL:https://trends.google.ru/trends/?geo=RU (accessed: 05.10.2019).

[8] Ministry of economic development of the Novosibirsk region [Electronic resource] // Government of the Novosibirsk region: [site].

URL:https://econom.nso.ru/page/262 (accessed: 10/16/2019).

[6] UNWTO [Electronic source]// UNWTO Tourism

Data Dashboard [website].

URL:https://www.unwto.org/unwto-tourism-dashboard (accessed: 27.11.2019). 